\title{
Phylogenetic position of a renal coccidium of the European green frogs, 'Isospora' lieberkuehni Labbé, 1894 (Apicomplexa: Sarcocystidae) and its taxonomic implications
}

1 Department of Parasitology, University of Veterinary and Pharmaceutical Sciences, Palackého 1-3, 61242 Brno, Czech Republic

2,3 Institute of Parasitology, Czech Academy of Sciences ${ }^{2}$ and and Faculty of Biology, University of South Bohemia ${ }^{3}$, České Budějovice, Czech Republic

\author{
David Modrý, 1,2 Jan R. Šlapeta, 1,2 Milan Jirků, ${ }^{2,3}$ Miroslav Oborník, ${ }^{2,3}$ \\ Julius Lukeš ${ }^{2,3}$ and Břetislav Koudela ${ }^{1,2}$
}

Author for correspondence: David Modrý. Tel: +420 5 41562979. Fax: +420 5748841. e-mail: modryd@vfu.cz

\begin{abstract}
'Isospora' lieberkuehni, an unusual isosporoid renal coccidium that parasitizes the European water frog was isolated from the edible frog, Rana kl. esculenta, in the Czech Republic. Sequencing of the small-subunit (SSU) rRNA gene showed that it belongs to the family Sarcocystidae, being closely related to a clade comprising members of the subfamily Toxoplasmatinae. The position within Sarcocystidae correlates with the mode of excystation via collapsible plates as postulated by previous authors. Phylogenetic, morphological and biological differences between 'Isospora' lieberkuehni and the other Stiedabody-lacking members of the genus Isospora justify separation of this coccidium on a generic level. Hyaloklossia Labbé, 1896 is the oldest available synonym and is herein re-erected. The original definition of the genus Hyaloklossia is emended based on recent observations.
\end{abstract}

Keywords: Isospora lieberkuehni, Hyaloklossia, Sarcocystidae, Coccidia, phylogenetic analysis

\section{INTRODUCTION}

The families Eimeriidae and Sarcocystidae of the Apicomplexa represent a highly diversified group of intracellular parasites of vertebrate and invertebrate hosts. The traditional classification of these parasites based on the number of sporocysts per oocyst was repeatedly questioned and its more or less artificial character was discussed (e.g. Box et al., 1980; Frenkel, 1977). The growing amount of molecular data on various species of coccidia enables us to draw a more accurate picture of the phylogeny of these parasites. The SSU rRNA gene has been shown to provide good phylogenetic resolution at the generic and/or specific levels and, based on its sequences, the phylogenetic

This paper was presented at the XIIIth meeting of the International Society for Evolutionary Protistology in České Budějovice, Czech Republic, 31 July-4 August 2000.

Sequence alignments from this paper are available as supplementary data in IJSEM Online (http://ijs.sgmjournals.org).

Abbreviation: Tv/Ts ratio, transversion/transition ratio.

The GenBank accession number for the SSU rRNA sequence of Hyaloklossia lieberkuehni is AF298623. positions of several members of the medically important families Eimeriidae and Sarcocystidae (mostly from domestic animals and man) were determined and repeatedly used in diagnostics and taxonomy (Barta et al., 1997; Eberhard et al., 1999; Ellis et al., 1998; Votypka et al., 1998). The assemblage of coccidia sharing the 'two sporocyst, each with four sporozoites' type of oocyst represents the taxonomically most complex and probably artificial group. It comprises medically important genera Besnoitia, Hammondia, Isospora, Neospora, Sarcocystis and Toxoplasma, and its phylogeny and taxonomy attracted much attention in recent years (Doležel et al., 1999; Ellis et al., 1998; Jenkins et al., 1999; Johnson, 1998; Mehlhorn \& Heydorn, 2000; Mugridge et al., 1999a, b; Tenter \& Johnson, 1997).

Recently, the genus Isospora was found to be polyphyletic, consisting of two distantly related clades. The Isospora species that contain the Stieda and substieda bodies and are parasites of birds showed close affinity to the Eimeriidae, while the Isospora species from mammalian hosts, having sutures in the sporocyst wall and lacking the Stieda and substieda bodies, grouped together within branch A (sensu Doležel et al., 1999) of 

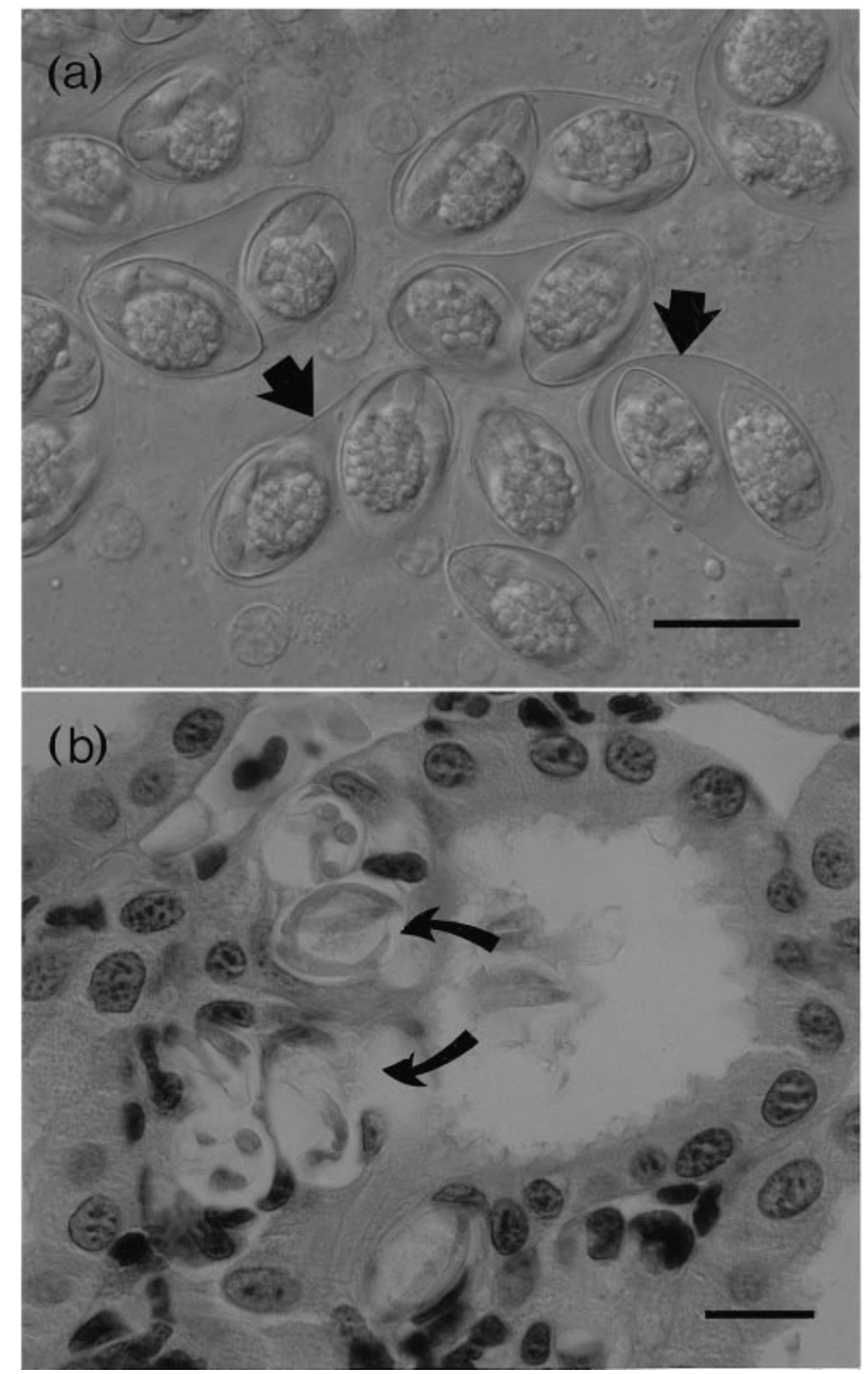

Fig. 1. (a) Nomarski interference contrast photograph of sporulated oocysts of Hyaloklossia lieberkuehni in squash preparation of frog kidney. Note thin, elastic and collapsible oocyst wall (arrows). (b) Histological section through tubules of infected kidney, showing several in situ sporulated oocysts of $H$. lieberkuehni (curved arrows). Bars, $20 \mu \mathrm{m}$.
Sarcocystidae (Carreno \& Barta, 1999). However, the diversity of parasites belonging to the genus Isospora, as it is presently defined, is probably higher and requires more attention.

The renal coccidium of water frogs of the genus Rana reported first by Lieberkühn in 1854 represents a species with several unique features. It was described by Labbé under the name Klossia lieberkuehni and, 2 years later, the same author re-evaluated its status and erected the genus Hyaloklossia to accommodate this unusual species (Lieberkühn, 1854; Labbé, 1894, 1896). However, later authors made Hyaloklossia synonymous with Diplospora Labbé, 1893 (Laveran \& Mesnil, 1902; Minchin, 1903) and later with Isospora Schneider, 1881 (Nöller, 1923; Doflein \& Reichenow,
1929). The combination of direct life cycle, extraintestinal development, in situ sporulation and unusual oocyst morphology distinguish 'Isospora' lieberkuehni from other members of the genus Isospora as well as from members of the Sarcocystidae. Here we present a phylogenetic analysis of this parasite and discuss its taxonomic implications.

\section{METHODS}

Organism. 'Isospora' lieberkuehni was isolated from the edible frog, Rana kl. esculenta Linnaeus, 1758, collected in Lanžhot, Southern Moravia, Czech Republic $\left(48^{\circ} 43^{\prime} \mathrm{N}\right.$, $16^{\circ} 58^{\prime} \mathrm{E}$ ), in May 1999 and during the spring of 2000. Frogs were dissected and infected kidneys were examined by using native squash preparations and processed for histology. 
Oocysts were examined, measured and photographed using Nomarski interference contrast optics. Heavily infected kidney tissue was preserved in absolute ethanol.

DNA extraction, PCR and sequencing. Total cell DNA from 'I.' lieberkuehni was isolated as described previously (Votypka et al., 1998). The SSU rRNA gene was PCR amplified with the oligonucleotides K11 (AAAGATTAAGCCATGCA) and K12 (CAAAGGGCAGGGACGTA), which anneal to the conserved $5^{\prime}$ and $3^{\prime}$-end regions of the gene. Conditions were as follows: initial denaturation $95^{\circ} \mathrm{C}$ for $4 \mathrm{~min}$ followed by 30 cycles at $95^{\circ} \mathrm{C}$ for $1 \mathrm{~min}, 50{ }^{\circ} \mathrm{C}$ for $1 \mathrm{~min}, 72^{\circ} \mathrm{C}$ for $1.5 \mathrm{~min}$ and a final extension at $72{ }^{\circ} \mathrm{C}$ for 10 min. The amplicon was purified on $0.75 \%$ agarose gels, gelisolated and cloned using the TOPO TA Cloning version E (Invitrogen). Both strands were sequenced on an automated sequencer using BigDye DNA Sequencing Kit (PerkinElmer).

Phylogenetic analysis. Based on taxonomic position, biology and morphology, a set of coccidian species was selected to cover the biodiversity of the Sarcocystidae and Eimeriidae; Cryptosporidium parvum or members of the Eimeriidae (data not shown) were used as outgroup(s). Only reliable SSU rRNA sequences as of November 2000 were obtained from the GenBank/EMBL/DDJB databases and were adopted in this phylogenetic analysis.

The SSU rRNA genes were aligned together with the newly sequenced 'I.' lieberkuehni using the program CLUSTAL X (Thompson et al., 1997). The dataset was analysed with a variety of alignment parameters and varying numbers of sequences. The stability was tested with different numbers of representatives of the groups. Alignment was corrected by eye and ambiguously aligned regions were excluded. Since we were primarily interested in the position of ' $I$.' lieberkuehni, the $5^{\prime}$ and $3^{\prime}$ regions not available in our sequence were removed from the alignment. Sequence alignments were analysed with the program package PAUP*, Version 4.0b4 (Swofford, 1998) and are available as supplementary data in IJSEM Online at (http://ijs. sgmjournals.org/). Phylogenetic relationships were reconstructed using the distance, parsimony and maximumlikelihood methods. The distance method was performed by using heuristic search with the ME objective setting, LogDet and HKY85 matrices. Parsimony and maximum-likelihood analyses were performed using heuristic settings with gaps treated as missing data and transversion/transition (Tv/Ts) ratios of $1: 1$ and $1: 3$. Maximum-likelihood was performed using the heuristic search and a substitution type 6 (GTR model), and tested also by the Puzzle algorithm. Bootstrap analysis (200 replicates for maximum-likelihood, 1000 replicates for maximum-parsimony and distance method) and the Bremer decay indexes (number of extra steps for a clade not to be unequivocally supported) were established.

\section{RESULTS AND DISCUSSION}

\section{Morphology and biology}

The endogenous stages of 'I.' lieberkuehni were found in $25 \%(n=16)$ of frogs of different age groups captured in April and May, while no infection $(n=18)$ was detected in July. The only stages observed were mature gamonts and oocysts located in the epithelium of renal tubules (Fig. 1b). In situ sporulated oocysts of 'I.' lieberkuehni were bisporocystic, elongated, with very thin elastic oocyst wall, $35-45 \times 20-25 \mu \mathrm{m}$, each

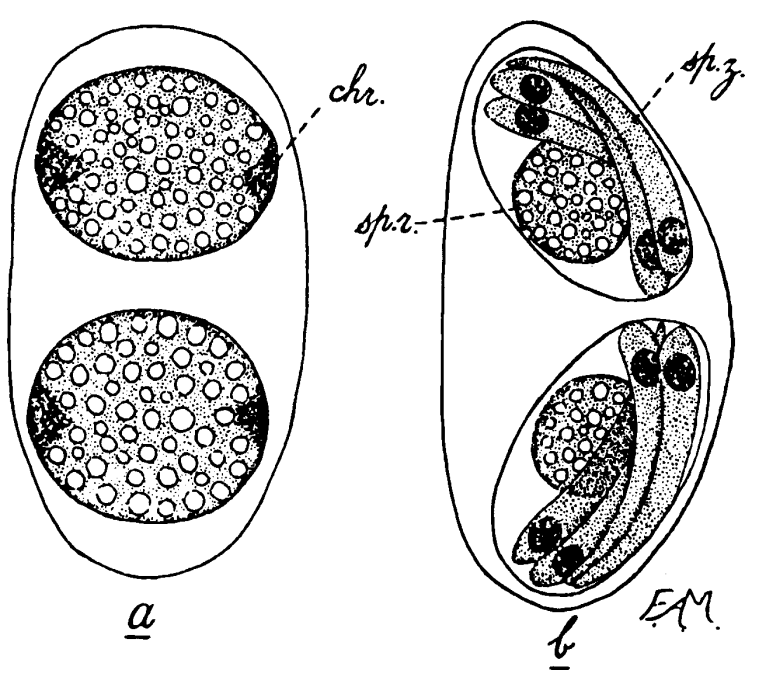

Fig. 2. The available drawings of (a) partly and (b) fully sporulated oocyst of $H$. lieberkuehni. Reprinted from Minchin (1903), after Laveran \& Mesnil (1902).

with two sporocysts. Sporocysts were broadly spindleshaped, $25-30 \times 14-16 \mu \mathrm{m}$, lacking the Stieda and substieda bodies. Sporozoites (four in each sporocyst) were elongated, banana-shaped, $17-21 \times 3-4 \mu \mathrm{m}$ in size. The sporocyst residuum appeared as a spherical to subspherical cluster of irregular granules (Fig. 1a). Many sporocysts liberated from ruptured oocysts were observed in the renal tubules. The morphology, localization of the endogenous stages and the host of the studied coccidium fit well with the original description of Klossia lieberkuehni, as well as with the observations of 'I.' lieberkuehni by later authors (Kazubski \& Grabda-Kazubska, 1973; Labbé, 1894; Laveran \& Mesnil, 1902) (Fig. 2). Observed seasonal occurrence is in agreement with an earlier report by Nöller (1923). Simple experiments described by this author also proved the direct life cycle, clearly distinguishing this parasite from members of the Sarcocystinae. It is probable that the endogenous development of this coccidium depends on the seasonal breeding of water frogs. The development in renal tubules and consequent release of oocysts culminate during spring when the breeding activity of frogs peaks and the oocysts are discharged into the aquatic environment represent a source of infection for the developing tadpoles. However, further research is required to settle this issue.

Generally, there are two modes of excystation of the Isospora species and the excystation structures seem to represent an important feature for classification (Box et al., 1980). Whereas some species do excyst by a collapse of plates, in other species excystation occurs by an escape of sporozoites through an opening in the sporocyst wall plugged by the Stieda body (Speer et al., 1973). Carreno \& Barta (1999) recently demonstrated a strong correlation between the mode of excystation and phylogeny. The phylogenetic position of ' $I$.' 


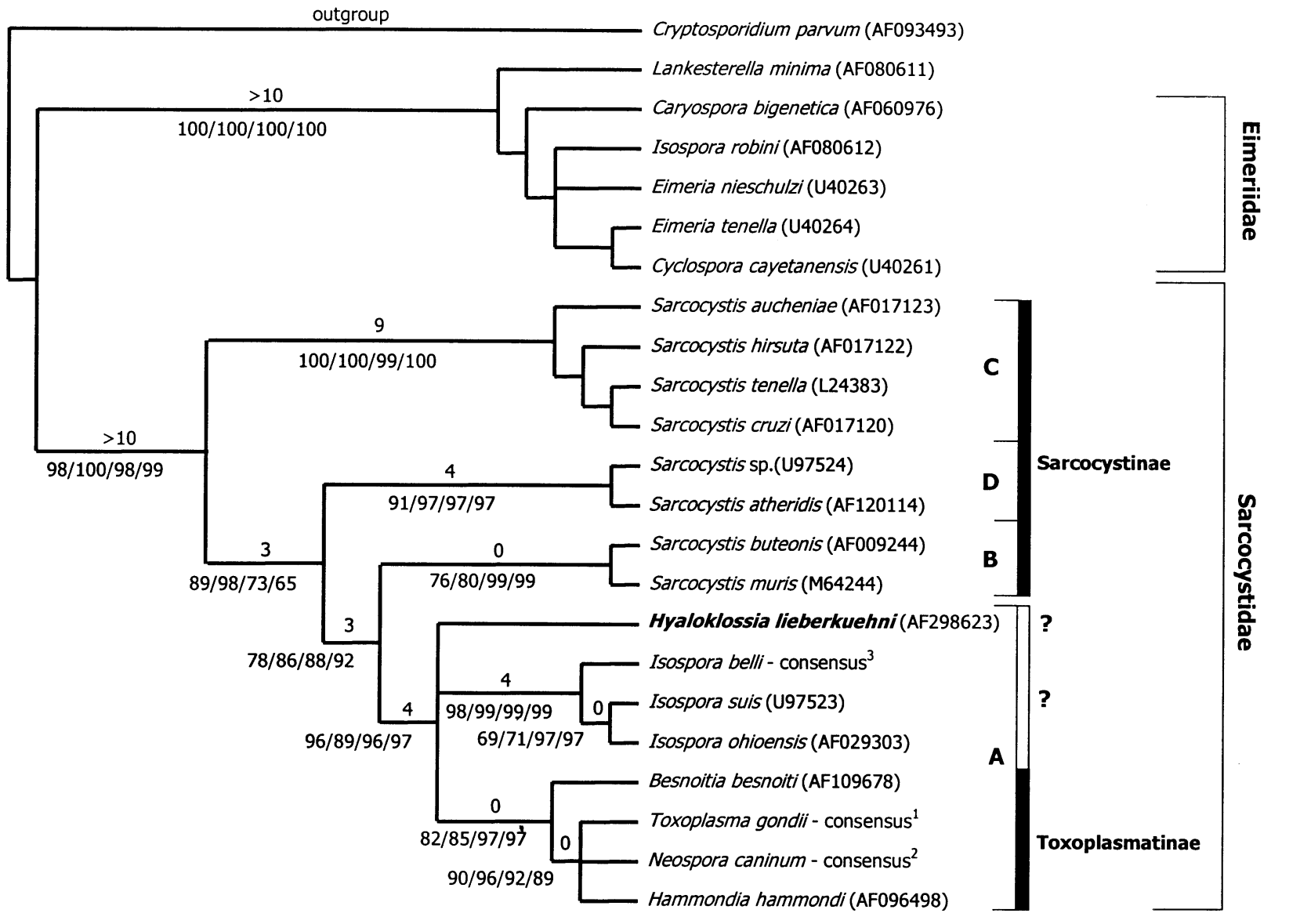

Fig. 3. Maximum-parsimony tree of the SSU rRNA sequences rooted at Cryptosporidium parvum; $50 \%$ majority rule strict consensus of 30 most parsimonious trees $(\mathrm{TV} / \mathrm{Ts}=1: 1 ; 790$ steps $; \mathrm{Cl}=0.71 ; \mathrm{RI}=0.78)$. Bootstrap values $(\mathrm{MP} \mathrm{TV} / \mathrm{Ts}=1: 1 ;$ MP Tv/Ts = 1:3; distance methods LogDet and HKY85) are shown below and the Bremer's indices above the line. The generally accepted taxonomic classification is indicated to the right. Consensus sequences: ${ }^{1}$ Toxoplasma gondii, from L37415, U12138, L24381, X65508, U03070, U00458, M97703, X68523, X75453, X75429 and X75430; ${ }^{2}$ Neospora caninum, from L23380, U03069, U16159 and U17346; and ${ }^{3}$ Isospora belli, from U94787 and AF10693.

lieberkuehni within the Sarcocystidae correlates well with the absence of the Stieda and substieda bodies in its sporocysts.

\section{Phylogenetic analysis}

The phylogenetic position of 'I.' lieberkuehni was evaluated by analysing the SSU rRNA gene. From oocysts isolated from the frog's kidney, an almost fulllength (1564 bp long) region of the SSU rRNA was sequenced. The analysis was based on a final alignment (1730 bp long) consisting of 23 taxa, from which ambiguously aligned areas (113 bp) were removed.

The studied isolate clusters within Sarcocystidae in a major group (branch A sensu Doležel et al., 1999) that comprises medically important parasites of the subfamily Toxoplasmatinae. This branch contains three clades supported by high bootstrap values (Fig. 3): (i) the Isospora species lacking the Stieda body (all parasites of mammals); (ii) the 'heteroxenous' coccidia (Neospora/Hammondia/Toxoplasma/Besnoitia); (iii) 'I.' lieberkuehni. All methods used strongly support monophyly of branch A and clades (i) and (ii) (Fig. 3), however, the position of 'I.' lieberkuehni within branch $\mathrm{A}$ is unstable. Both matrices used in the distance method placed the studied species as an ancestral representative of branch $\mathrm{A}$, however, with a low bootstrap support $(59 \% ; 61 \%)$. Certain degree of instability of the 'I.' lieberkuehni clade is manifested in the maximum-likelihood tree $(-\ln =6771.68832)$, where it was placed an ancestral representative of branch A $(50 \%)$ (Fig. 4). Moreover, the Puzzle algorithm further supported this branching order $(83 \%)$ (data not shown). In the maximum-parsimony analysis (234 and 202 informative and non-informative sites, respectively; $\mathrm{Tv} / \mathrm{Ts}=1: 1 ; 30$ most parsimonious trees; 790 steps; $\mathrm{CI}=0.71$; $\mathrm{HI}=0.78$ ) our isolate branched off on the basis of branch A (49\%), while a change of $\mathrm{Tv} / \mathrm{Ts}$ ratio to $1: 3$ (six most parsimonious trees; 1406 steps $; \mathrm{CI}=0.73 ; \mathrm{HI}=0 \cdot 80$ ) resulted in its placement as a sister taxon to the Isospora clade $(45 \%)$. Taken together, these results show a 'trichotomy', caused by a lack of resolution within the above-mentioned clades within branch A. 


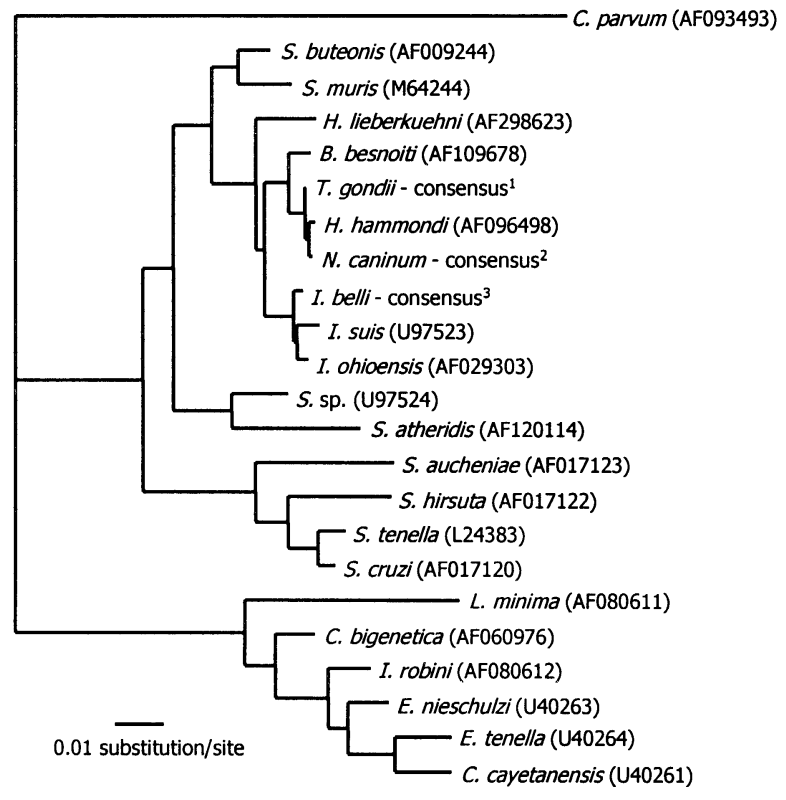

Fig. 4. Maximum-likelihood tree of the SSU rRNA sequences rooted at Cryptosporidium parvum. The distance scale is given under the tree. See the legend to Fig. 3 for accession numbers for consensus sequences.

Sequencing the D2 domain or the entire large-subunit rRNA gene may resolve the exact position of ' $I$.' lieberkuehni within branch $\mathrm{A}$, as has been shown previously for related species (Ellis et al., 1999; Mugridge et al., 1999b). The overall branching of the trees is in good agreement with the topologies published by other authors (Doležel et al., 1999; Jenkins et al., 1999; Holmhahl et al., 1999).

Traditionally, the family Sarcocystidae is divided into two subfamilies, Sarcocystinae and Toxoplasmatinae. Recently, Jenkins et al. (1999) have also included mammalian Isospora spp. (lacking the Stieda body) into the latter subfamily, without any respect to the widely accepted definition of the Toxoplasmatinae (e.g. Frenkel et al., 1987). More biological, morphological and molecular data on isosporoid coccidia are necessary to resolve the division of Sarcocystidae into the concise subfamilies.

\section{Taxonomy}

The unique combination of morphological, biological and phylogenetic feature is, in our opinion, sufficient for the separation of 'Isospora' lieberkuehni on the generic level. The homoxenous life cycle distinguishes it from Sarcocystis and the exogenous sporulation and extraintestinal development from the mammalian Isospora spp. and members of the Toxoplasmatinae.

Hyaloklossia Labbé, 1896 is the oldest available synonym and should therefore be re-erected. However, the definition of the genus Hyaloklossia given by Labbé (1896) is insufficient and should be corrected on the basis of recent observations.

\section{Emended genus definition of Hyaloklossia Labbé, 1896 (Apicomplexa: Sarcocystidae)}

Oocysts bisporocystic, with a thin, elastic, relatively fragile oocyst wall; sporocysts tetrazoic; sporocyst wall composed of plates joined by sutures; Stieda and substieda bodies absent. Life cycle is homoxenous, endogenous development extraintestinal; sporulation of oocysts typically endogenous (in situ). Type species: Hyaloklossia lieberkuehni (Labbé, 1894). Type host: Rana kl. esculenta L.

\section{ACKNOWLEDGEMENTS}

This study was supported by grants from the Grant Agency of the Czech Academy of Sciences nos. A6022903 and B5022904 and from the Grant Agency of the Czech Republic no. 524/00/P015. We thank Veronika Schacherlová for the preparation of samples for histology and Václav Hypša for assistance with phylogenetic methods.

\section{REFERENCES}

Barta, J. R., Martin, D. S., Liberator, P. A. \& 9 other authors (1997). Phylogenetic relationships among eight Eimeria species infecting domestic fowl inferred using complete small subunit ribosomal DNA sequences. J Parasitol 83, 262-271.

Box, E. D., Marchiondo, A. A., Duszynski, D. W. \& Davis, C. P. (1980). Ultrastructure of Sarcocystis sporocysts from passerine birds and opossums: comments on classification of the genus Isospora. J Parasitol 66, 68-74.

Carreno, R. A. \& Barta, J. R. (1999). An Eimeriid origin of isosporoid coccidia with Stieda bodies as shown by phylogenetic analysis of small subunit ribosomal RNA gene sequences. $J$ Parasitol 85, 77-83.

Doflein, F. \& Reichenow, E. (1929). Lehrbuch der Protozoenkunde, 5th edn, pp. 960-961. Jena: Gustav Fischer.

Doležel, D., Koudela, B., Jirků, M., Hypša, V., Oborník, M., Votypka, J., Modrý, D., Šlapeta, J. R. \& Lukeš, J. (1999). Phylogenetic analysis of Sarcocystis spp. of mammals and reptiles supports the coevolution of Sarcocystis spp. with their final hosts. Int J Parasitol 29, 795-798.

Eberhard, M. L., da Silva, A. J., Lilley, B. G. \& Pieniazek, N. J. (1999). Morphologic and molecular characterization of new Cyclospora species from Ethiopian monkeys: C. cercopitheci sp.n., C. colobi sp.n., and C. papionis sp.n. Emerg Infect Dis 5, 651-658.

Ellis, J. T., Morrison, D. A. \& Jeffries, A. C. (1998). The Phylum Apicomplexa: an update on the molecular phylogeny. In Evolutionary Relationships Among Protozoa, pp. 255-274. Edited by G. H. Coombs, K. Vickerman, M. A. Sleigh \& A. Warren. London: Chapman \& Hall.

Ellis, J. T., Morrison, D. A., Liddell, S., Jenkins, M. C., Mohammed, O. B., Ryce, C. \& Dubey, J. P. (1999). The genus Hammondia is paraphyletic. Parasitology 118, 357-362.

Frenkel, J. K. (1977). Besnoitia wallacei of cats and rodents: With a reclassification of other cystforming isosporoid coccidia. $J$ Parasitol 63, 611-628.

Frenkel, J. K., Mehlhorn, H. \& Heydorn, A. O. (1987). Beyond the oocyst: over the molehills and mountains of coccidialand. Parasitol Today 3, 250-252.

Holmdahl, O. J., Morrison, D. A., Ellis, J. T. \& Huong, L. T. (1999). Evolution of ruminant Sarcocystis (Sporozoa) parasites based 
on small subunit rDNA sequences. Mol Phylogenet Evol 11, $27-37$.

Jenkins, M. C., Ellis, J. T., Liddell, S., Ryce, C., Munday, B. L., Morrison, D. A. \& Dubey, J.P. (1999). The relationship of Hammondia hammondi and Sarcocystis mucosa to other heteroxenous cyst-forming coccidia as inferred by phylogenetic analysis of the $18 \mathrm{~S} \mathrm{SSU}$ ribosomal DNA sequence. Parasitology 119, 135-142.

Johnson, A. M. (1998). Is there more than one species in the genus Toxoplasma? Tokai J Exp Clin Med 23, 383-389.

Kazubski, S. L. \& Grabda-Kazubska, B. (1973). Isospora lieberkuehni (Labbé, 1896) and I. neos Yakimoff and Gousseff, 1936 (Eimeriidae) in frogs in Poland. Acta Parasitol Pol 21, 3-8.

Labbé, A. (1894). Recherches zoologiques, cytologiques et biologiques sur les parasites endoglobulaires du sang vertebres. Arch Zool Exp Gen (Ser 3) 2, 55-258.

Labbé, A. (1896). Recherches zoologiques, cytologiques et biologiques sur les coccidies. Arch Zool Exp Gen (Ser 3) 4, 517-654.

Laveran, M. A. \& Mesnil, F. (1902). Sur la coccidie trouvée dans le rein de la Rana esculenta et sur l'infection generale qu'elle produit. C R Acad Sci (Paris) Ser 3 135, 82-87.

Lieberkühn, N. (1854). Über die Psorospermien. Arch Anat Physiol Wissensch Med (Berlin) 1854, 349-368.

Mehlhorn, H. \& Heydorn, A. O. (2000). Neospora caninum: is it really different from Hammondia heydorni or is it a strain of Toxoplasma gondii?An opinion. Parasitol Res 86, 169-178.

Minchin, E. A. (1903). The Sporozoa. In Treatise on Zoology. Introduction and Protozoa, p. 231. Edited by E. R. Lankester. London: Adam \& Charles Black.

Mugridge, N. B., Morrison, D. A., Johnson, A. M., Luton, K.,
Dubey, J. P., Votypka, J. \& Tenter, A. M. (1999a). Phylogenetic relationships of the genus Frenkelia: a review of its history and new knowledge gained from comparison of large subunit ribosomal ribonucleic acid gene sequences. Int $J$ Parasitol 29, 957-972.

Mugridge, N. B., Morrison, D. A., Heckeroth, A. J., Johnson, A. M. \& Tenter, A. M. (1999b). Phylogenetic analysis based on fulllength large subunit ribosomal RNA gene sequence comparison reveals that Neospora caninum is more closely related to Hammondia heydorni than to Toxoplasma gondii. Int J Parasitol 29, 1545-1556.

Nöller, W. (1923). Zur Kenntnis eines Nierencoccids. Der Entwicklungskreis des Coccids der Wasserfroschniere [Isospora lieberkuhni (Labbe, 1894)]. Arch Protistenkd 47, 101-108.

Speer, C. A., Hammond, D. M., Mahrt, J. L. \& Roberts, W. L. (1973). Structure of the oocyst and sporocyst walls and excystation of sporozoites of Isospora canis. J Parasitol 59, 35-40.

Swofford, D. L. (1998). PAUP*: Phylogenetic Analysis Using Parsimony, Version 4.0b4. Sunderland, MA: Sinauer Associates.

Thompson, J. D., Gibson, T. J., Plewniak, F., Jeanmougin, F. \& Higgins, D. G. (1997). The CLUSTAL X windows interface: flexible strategies for multiple sequence alignment aided by quality analysis tools. Nucleic Acids Res 24, 4876-4882.

Tenter, A. M. \& Johnson, A. M. (1997). Phylogeny of the tissue cyst-forming coccidia. Adv Parasitol 39, 70-139.

Votýpka, J., Hypša, V., Jirků, M., Flégr, J., Vávra, J. \& Lukeš, J. (1998). Molecular phylogenetic relatedness of Frenkelia spp. (Protozoa, Apicomplexa) to Sarcocystis falcatula Stiles, 1893: is the genus Sarcocystis paraphyletic? J Eukaryot Microbiol 45, 137-141. 